DOI 10.37882/2223-2982.2021.10-2.07

\title{
АНАЛИЗ ЯЗЫКОВОЙ ОНТОЛОГИЗАЦИИ ЭПИСТЕМИЧЕСКОГО ФАКТОРА В АСПЕКТЕ ОСМЫСЛЕНИЯ ТЕМЫ ВЫСКАЗЫВАНИЯ
}

\section{ANALYSIS OF THE LANGUAGE ONTOLOGIZATION OF THE EPISTEMIC FACTOR IN THE ASPECT OF IMPLEMENTING THE TOPIC OF THE STATEMENT \\ D. Vorotnikov \\ T. Pankova}

Summary: The purpose of this study is to determine how the ontologization of the epistemic factor affects the process of the interlocutor's comprehension of the topic of the utterance, the contextualization of the utterance as a whole. The scientific novelty lies in the fact that for the first time the analysis of the features of verbal linguistic markers is carried out in the context of the contextualization of the topic. The results obtained indicate that representation is carried out through quotation or retelling, which is often accompanied by a shift in the deictic coding of time and place, a change in pronouns and the sequence of tenses. The following verbal means are markers of indirect access to information: indirect appeal, passive voice of verbs, lexical introductory units. It is emphasized that the use of the cognitive components of communication, aimed at minimizing the attempts of the interlocutors in the contextualization of the topic, contributes to the optimization of communicative interaction.

Keywords: verbal linguistic markers, linguistic ontologization, communicative partner, current communicative situation, aspect of comprehension, contextualization of an utterance, intellectual distance.
Воротников Дмитрий Валерьевич

Преподаватель, Российский государственный социальный университет (Москва) ivasha2509@gmail.com

Панкова Татьяна Николаевна к.филол.н., Доцент, Воронежский государственный университет pankovatn30@mail.ru

Аннотация: Цель настоящего исследования - определить каким образом онтологизация эпистемического фактора влияет на процесс осмысления собеседником темы высказывания, на контекстуализации высказывания в целом. Научная новизна состоит в том, что впервые проводится анализ особенностей вербальных языковых маркеров в условиях контекстуализации темы. Полученные результаты свидетельствуют о том, что репрезентация осуществляется посредством цитирования или пересказа, который часто сопровождается смещением дейктического кодирования времени и места, заменой местоимений и последовательности времен. Маркерами опосредованного доступа к информации являются следующие вербальные средства: косвенное обращение, пассивный залог глаголов, лексические вводные единицы. Подчеркивается, что задействование когнитивных компонентов коммуникации, направленных на минимизацию попыток собеседников в контекстуализации темы, способствует оптимизации коммуникативного взаимодействия.

Ключевые слова: вербальные языковые маркеры, языковая онтологизация, коммуникативный партнер, текущая коммуникативная ситуация, аспект осмысления, контекстуализация высказывания, интеллектуальная дистанция.
$\mathrm{B}$ центре внимания данной статьи - построение смысла и, следовательно, ключевые вопросы о том, что нам нужно знать, чтобы понимать друг друга, и какого рода знания, относящиеся к пониманию, нам необходимы. Понимание здесь означает обретение смысла в реальных ситуациях. Процесс смыслообразования и, следовательно, контекстуализации встроен в ситуацию, в которой он происходит. Основной интерес представляет рассмотрение высказываний как данных в процессе человеческого взаимодействия и оказывающих воздействие на нашу психику, а также понимание этого воздействия. В работе рассматривается актуальность металингвистического, метапрагматического осознания в коммуникации.

Употребление языка всегда интерпретируется, то есть участники коммуникации придают ему определённое значение. Следовательно, рефлексивное осознание является важнейшим аспектом процессов смыслопорождения. Это осознание отражается в том, как высказывания/тексты располагаются во временном, истори- ческом, социальном контексте. Без такой контекстной «встроенности» любая интерпретация невозможна, или «не существует возможности интерактивной связности» $[12$, c. 78$]$.

К сегодняшнему дню накопился большой фактический материал, свидетельствующий о формировании «мышления под влиянием языка» $[2,3,4,5,13,14,20$, 21]. Если в классических теориях познания господствовал принцип единства познания и языка, в духе идеи единства формы и содержания, то теперь, используя терминологию Аристотеля, язык предстает не только и не столько формальной основой, сколько активно изменяющей основой, производящей, движущей причиной.

В продолжающихся дискуссиях о способах создания смысла центральное место занимают понятия контекста и интеракциональной модели коммуникации [2, с. 165]. Под контекстом мы понимаем экстралингвистическое окружение высказывания/текста, которое делает его прагматически и социокультурно релевантным. Таким 
образом, отправной точкой в анализе построения значения является то, что референциальное или денотативное значение - это только одна часть эффектов использования языка. Текст, рассматриваемый в фокусе динамического процесса, рассматривается как постоянная семантизация, как кластер различных значений, которые либо реализуются, либо не реализуются в конкретных контекстах [3, с. 419]. Помимо референциального значения, акты коммуникации, безусловно, порождают социальное значение, то есть интерпретационные связи между тем, что было сказано, и социальным поводом, в котором это было сделано [6, с. 623].

Хотя формальные структуры и пропозициональное значение предложений в данном случае имеют значение, они больше не являются доминирующими в изучении языка и интерпретации значения. Значение вытекает из ситуации [4, с. 394].

Однако контекст больше не рассматривается как внешний объект, просто добавляемый к лингвистическому анализу в качестве «побочного продукта» [7]. Способ, в котором слово или высказывание «вписывается в контекст - это то, что создает смысл для других» [8, с. 133]. Говоря иначе, придать смысл слову или высказыванию означает установить соответствующие связи между использованием языка и конкретными условиями, в которых он функционирует, должным образом его контекстуализировать [5, с. 154].

Таким образом, еще одним ключевым понятием для данного обсуждения является контекстуализация. Мы рассматриваем контекстуализацию как когнитивный и вербальный процесс выдвижения на передний план, выделения говорящим и понимания адресатом некоторых компонентов контекста как основных и важнейших смысловых сигналов, задающих рамки и перспективы интерпретации сообщаемого в виде вербальных структур.

Контекстуализация не является однозначной и беспроблемной. Почти нет ограничений на какие-либо внешние факторы, релевантные для конкретного речевого акта «Нет никаких принципиальных ограничений на то, что может быть включено в данный контекст, на то, что может быть показано как действительно релевантное для совершения конкретного речевого акта» [9, с. 255].

Выявление релевантных компонентов контекста, имеющих решающее значение для эффективного извлечения смысла, не может быть осуществлено с помощью формальных процедур. Эта проблема не имеет четкого технического решения. Исследовательский вопрос, на который необходимо ответить, заключается в том, как управлять и оперировать контекстом, то есть как выявить его релевантные аспекты, имеющие решающее значение для анализа данной коммуникативной ситуации и структуры текста в этой ситуации.

Контекстуализация может, например, резко пойти не так, особенно в ситуациях, когда речь идет о таких социально и/или политически чувствительных категориях, как раса, пол, этническая принадлежность. Неправильное распределение высказываний по контекстам приводит к непониманию и конфликтам.

Современное «панорамное» изучение контекста характеризуется тем, что контекст рассматривается уже не как чисто языковое окружение (со-текст) языковой единицы, а как совокупность языковых и неязыковых факторов, играющих важную роль в эффективном воспроизводстве и интерпретации дискурса.

Особенность данной статьи заключается в использовании когнитивно-коммуникативного подхода к изучению контекста высказывания. Согласно социокогнитивному подходу, предложенному Т.А. ван Дейком, контекст не рассматривается как объективная физическая среда, в которой происходит общение. Вместо этого мы имеем дело с моделями контекста - мысленно истолкованными субъективными репрезентациями соответствующих свойств коммуникативной ситуации в эпизодической памяти её участников [10, с. 72].

Решающим моментом является не ситуация сама по себе, взятая в её абсолютных измерениях, но определение этой ситуации участником, поскольку именно он выбирает соответствующие свойства своей реальной физического среды для текущего момента. Таким образом, ситуация является абстракцией, сформированной в результате ментальной обработки общего фона участника высказывания (сенсорного, интенционального, рационального) [11, с. 100].

К таким релевантным свойствам относятся параметры времени и места, собеседники и их различные идентичности, характеры, роли, действия, цели и знания. Это демонстрирует огромную важность принятия в качестве отправной точки для анализа контекста перспективу того участника, чьё поведение анализируется [15, с. 188]. Соответственно, в коммуникативной ситуации существуют как минимум две контекстные модели: контекстная модель говорящего и модель контекста слушающего, которые накладываются друг на друга в процессе коммуникации.

Тема как «объект мысли, сформировавшийся в сознании говорящего и выраженный в тексте» [16] может быть легко распознана и адекватно идентифицирована слушающим при условии учёта соответствующей контекстной модели.

Таким образом, тема и контекст находятся в фунда- 
ментальном отношении друг к другу. Контекстные модели характеризуются своим динамическим характером. Они развиваются «непрерывно» и «online», то есть параллельно с действием и мыслями [20, с. 248].

В рамках современной когнитивно-коммуникативной парадигмы наблюдается общая тенденция к переосмыслению контекста и определению его не как объективно существующего явления, а как специфических ментальных моделей, создаваемых собеседниками в процессе коммуникации и представляющих в их эпизодической памяти соответствующие свойства коммуникативной среды.

Соответственно, в процессе контекстуализации темы - лингвокогнитивной операции, направленной на конкретизацию темы - различные релевантные коммуникативные факторы (пространственно-временные, статусно-ролевые, эпистемические, аффективные) эксплицируются через призму их интерпретации партнерами по общению.

Основатель социокогнитивной теории контекста Т.А. ван Дейк предполагает, что «контексты, определяемые как ментальные модели, нуждаются в особом компоненте знаний», который представляет собой соответствующие убеждения о знаниях, говорящих или слушающих их собеседников. Другими словами, пользователям языка необходимо иметь не только общие «знания о мире», и не только знания о текущей коммуникативной ситуации, но и, конечно же, взаимные знания о знаниях друг друга. Эти предположения являются релевантными измерениями текущей коммуникативной ситуации [10, с. 78].

Коммуникативный статус эпистемического фактора контекстуализации темы предполагает задействование общих фоновых знаний и коммуникативной компетенции собеседников, представленных широким потенциалом вербального выражения в дискурсе.

Мы рассматриваем фоновые знания как общую для обоих коммуникативных партнеров имплицитную информацию, которая добавляется к содержанию вербального высказывания и позволяет оптимизировать его восприятие и понимание.

В нашем случае это общий пресуппозиционный (ситуативный и внеситуативный (социокультурный)) фонд говорящего и слушающего, без которого их совместное коммуникативное взаимодействие, направленное на контекстуализацию темы, будет блокировано или станет практически невозможным. Коммуникативная компетенция определяется как способность собеседников мобилизовать различные знания вербальных и невербальных средств, ситуации, правил и норм поведения, общества и культуры для эффективного выполнения определенных коммуникативных задач в соответствующих контекстах и ситуациях [11, с. 203].

Общая коммуникативная компетенция включает в себя такие составляющие, как лингвистическая компетенция, дискурсивная компетенция, социолингвистическая компетенция, социокультурная компетенция, стратегическая компетенция, иллокутивная компетенция и создает основу для дифференциации знаний, входящих в индивидуальное когнитивное пространство каждого коммуникативного партнера.

Безусловно, степень осведомленности собеседников о теме в начале (начальная осведомленность) и в конце (аддитивная осведомленность) коммуникации существенно различается. В процессе речевого взаимодействия коммуникативные партнеры приобретают и накапливают новую информацию об обсуждаемой теме, что способствует эффективной контекстуализации этой темы.

По мнению Т. Левандовской-Томашик, «Творчество в производстве языка - это взаимодействие между старым и новым. Новое не может быть произведено или понято человеком полностью независимо от знакомого материала. О нём можно думать либо в терминах перестройки и/или умножения известных стереотипных схем, либо в терминах введения новых элементов в существующие схемы путем установления новых связей между ними, их реконфигурации» $[17$, с. 98].

Говорящий (как инициатор контекстуализации темы) должен активизировать не только свои собственные знания, но и гипотетически моделировать знания своего коммуникативного партнера. Для этого он обычно применяет следующие K(knowledge)-стратегии [18, с. 4]:

1. К 1 - стратегия активизации уже имеющейся общей информации («Я рассказывал вам о..?», «Вы помните...», «Как я уже сказал ...»);

2. К 2 - стратегия введения новой информации путем объяснения некоторых новых фактов по теме.

Различия в знаниях формируют интеллектуальную дистанцию между собеседниками. Согласно результатам нашего исследования, чем меньше интеллектуальная дистанция, тем имплицитнее контекстуализация темы и, наоборот, чем больше интеллектуальная дистанция, тем эксплицитнее контекстуализация темы. Представляя свои знания о теме, говорящий указывает источник своих знаний и свою уверенность/неуверенность в осведомленности о теме. О градации эпистемического фактора в контекстуализации темы свидетельствует разработанная в лингвистике модально-эпистемическая шкала «знаю - предполагаю - не знаю» [19, с. 106].

Экспликация эпистемического фактора в дискурсе 
реализуется с помощью широкого спектра вербальных средств: глаголы (знать, понимать, определять, иметь в виду, убеждать, верить, сомневаться, казаться, думать, считать, предполагать, предполагать, предполагать, догадываться); модальные глаголы (должен, следует, должен, должен, может, нужно, нужно, будет, может, может, может, может, может, мог, будет); наречия (безусловно, конечно, действительно, фактически, несомненно, очевидно, уверенно, действительно, определенно, очевидно, явно, возможно, возможно, вероятно, предположительно); прилагательные (уверенный, знающий, уверенный, определенный, очевидный, истинный, неопределенный, вероятный, маловероятный, возможный, вероятный, сомнительный); существительные (уверенность, убежденность, несомненность, подтверждение, достоверность, факт, сомнение, предположение, неопределенность, невозможность, невероятность).

По способу получения знаний следует различать прямой и опосредованный доступ к информации. Прямой доступ к информации основан на индивидуальном перцептивном опыте партнеров по общению и охватывает область определенности («я знаю») на модально-эпистемической шкале, тогда как опосредованный доступ к информации занимает область неопределенности («я предполагаю», «я основываюсь на предположении», «я не знаю»).

Прямой доступ связан с явлением «визуального или аудиального свидетельства», другими словами, говорящий сам пережил или стал свидетелем определённого события. Речевые средства прямого доступа к информации представлены местоимениями 1-го лица (я, мы); глаголами чувственного восприятия - зрительного и слухового (видеть, смотреть, наблюдать, замечать, глаз, слушать, слышать).

Опосредованный доступ к информации предполагает, что говорящий не был непосредственным свидетелем ситуации и получил информацию с чужих слов или путём умозаключений. Он проводит чёткую демаркацию между собой и нами/автором сообщения, приписывая происхождение информации другим и в некоторой степени дистанцируясь от неё, тем самым перекладывая ответственность за точность информации на кого-то другого.

Полученные результаты свидетельствуют о том, что репрезентация опосредованного доступа осуществляется посредством цитирования или пересказа, который, как правило, сопровождается смещением дейктического кодирования времени и места, заменой местоимений и последовательности времен. Маркерами опосредованного доступа к информации являются следующие вербальные средства: косвенное обращение, представленное глаголами (говорить, рассказывать, информировать, отвечать, сообщать, реагировать, замечать); пассивный залог глаголов (было упомянуто, было объявлено); лексические вводные единицы (согласно, в соответствии с).

Задействование когнитивных компонентов коммуникации, направленных на минимизацию попыток собеседников в контекстуализации темы, способствует оптимизации коммуникативного взаимодействия.

Изучение вербализации эпистемического фактора в контекстуализации темы открывает новые векторы для дальнейших исследований гендерных и этнокультурных особенностей контекстуальных операций.

\section{ЛИТЕРАТУРА}

1. Ганюшина, М.А. Когнитивно-исследовательский метод обучению иноязычной лексики студентов нелингвистических факультетов в рамках лингвокультурологического подхода / М.А. Ганюшина, Н.С. Варфоломеева // Коммуникация в современном поликультурном мире: культура, образование, политика: Ежегодный сборник научных трудов / Ответственные редакторы Т.А. Барановская, Е.Н. Соловова. - Москва: Российское представительство ИздатеЛЬСТВа ПИРСОН ЭДЬЮКЕЙШН ЛИМИТЕД, 2018. - С. 8-15.

2. Сафонов, М.А. Оценочная детерминация при переводе / М.А. Сафонов // Современная наука: актуальные проблемы теории и практики. Серия: Гуманитарные науки. - 2018. - № 9. - С. 165-171.

3. Содержательно-подтекстовый слой информативности текста как способ выражения авторской модальности (на примере рассказа И.А. Бунина «в Париже») / Н.Л. Харченко, М.А. Сафонов, С.С. Усов [и др.] // Вестник Удмуртского университета. Серия История и филология. - 2018. - Т. 28. - № 3. - С. 419-428.

4. Усов, С.С. Содержательно-концептуальный аспект информативности политического дискурса (на примере «фултонской речи» у Черчилля) / С.С. Усов // Мировое культурно-языковое и политическое пространство: инновации в коммуникации: Сборник научных трудов / Под общей редакцией С.Н. Курбаковой, Н.М. Мекеко. - Москва: Российский университет дружбы народов (РУДН), 2018. - С. 394-400.

5. Харченко, Н.Л. Манипулятивные структуры в политическом дискурсе / Н.Л. Харченко // Научное обозрение. Серия 2: Гуманитарные науки. - 2015. № 2. - C. 154-158.

6. Barrett H.C. Towards a cognitive science of the human: cross-cultural approaches and their urgency //Trends in Cognitive Sciences. - 2020. - T. 24. - №. 8. C. 620-638.

7. Bombała B. The Question of Management Science Paradigms //Agathos: An International Review of the Humanities \& Social Sciences. - 2021. - T. 12 . - № . 1.

8. Castro J.A.G. Radical Solutions to the Ontological and Epistemological Problems of Consciousness //Psychiatry and Neuroscience Update. - Springer, Cham, 2021. - C. 131-140. 
9. Deryabin A., Popov A. Open data in open education: epistemological and didactic aspects //ARPHA Proceedings. - 2021. - T. 4. - C. 254.

10. Dijk T.A. Contextual Knowledge Management in Discourse Production. A CDA Perspective. A New Agenda in Critical Discourse Analysis / R. Wodak, P. Chilton. Amsterdam: Benjamins, 2005. P. 71-100.

11. Dijk T.A. Discourse and Context: A Sociocognitive Approach. New York: Cambridge University Press, 2008. 266 p.

12. Goulart D.M., Torres J.F.P. Qualitative Epistemology and Constructive-Interpretative Methodology: Contributions for Research in Social Sciences and Humanities // Theory of Subjectivity from a Cultural-Historical Standpoint. - Springer, Singapore, 2021. - C. 75-87.

13. Kafaee M., Taqavi M. The Value of «Traditionality»: The Epistemological and Ethical Significance of Non-western Alternatives in Science //Science and Engineering Ethics. - 2021. - T. 27. - №. 1. - C. 1-20.

14. Kidd C. The Skeptical Origins of Husserl's Transcendental Phenomenology //Husserl Studies. - 2021. - C. 1-23.

15. Kordeš U., Demšar E. Towards the epistemology of the non-trivial: Research characteristics connecting quantum mechanics and first-person inquiry //Foundations of Science. - 2021. - T. 26. - №. 1. - C. 187-216.

16. Kovalchuk L.V. Verbalization of the epistemic factor in topic contextualization //Publishing House "Baltija Publishing". - 2021.

17. Lewandowska-Tomaszczyk B. Convention and Creativity in Natural Language. Studia Auglica Posnaniensia. Poznon: Universitet im. Adama Mickiewicza w Poznanin, 1993. Vol.1. P. 97-105.

18. Lewandowska-Tomaszczyk, B. «Approximative Spaces and the Tolerance Threshold in Communication» International Journal of Cognitive Linguistics. - 2012. Vol. 2 (2), P. 2-19.

19. Lewandowska-Tomaszczyk, B. «Re-conceptualization and the Emergence of Discourse Meaning as a Theory of Translation». In Meaning in Translation, edited by B. Lewandowska-Tomaszczyk and M. Thelen, Frankfurt am Main: Peter Lang. - 2010, P. 105-148.

20. Ruse M. The view from somewhere: A critical defense of evolutionary epistemology //Philosophy after Darwin. - Princeton University Press, 2021. - C. 247-275.

21. Vincini S. The Epistemological Contribution of the Transcendental Reduction //Husserl Studies. - 2021. - T. 37. - C. 39-66.

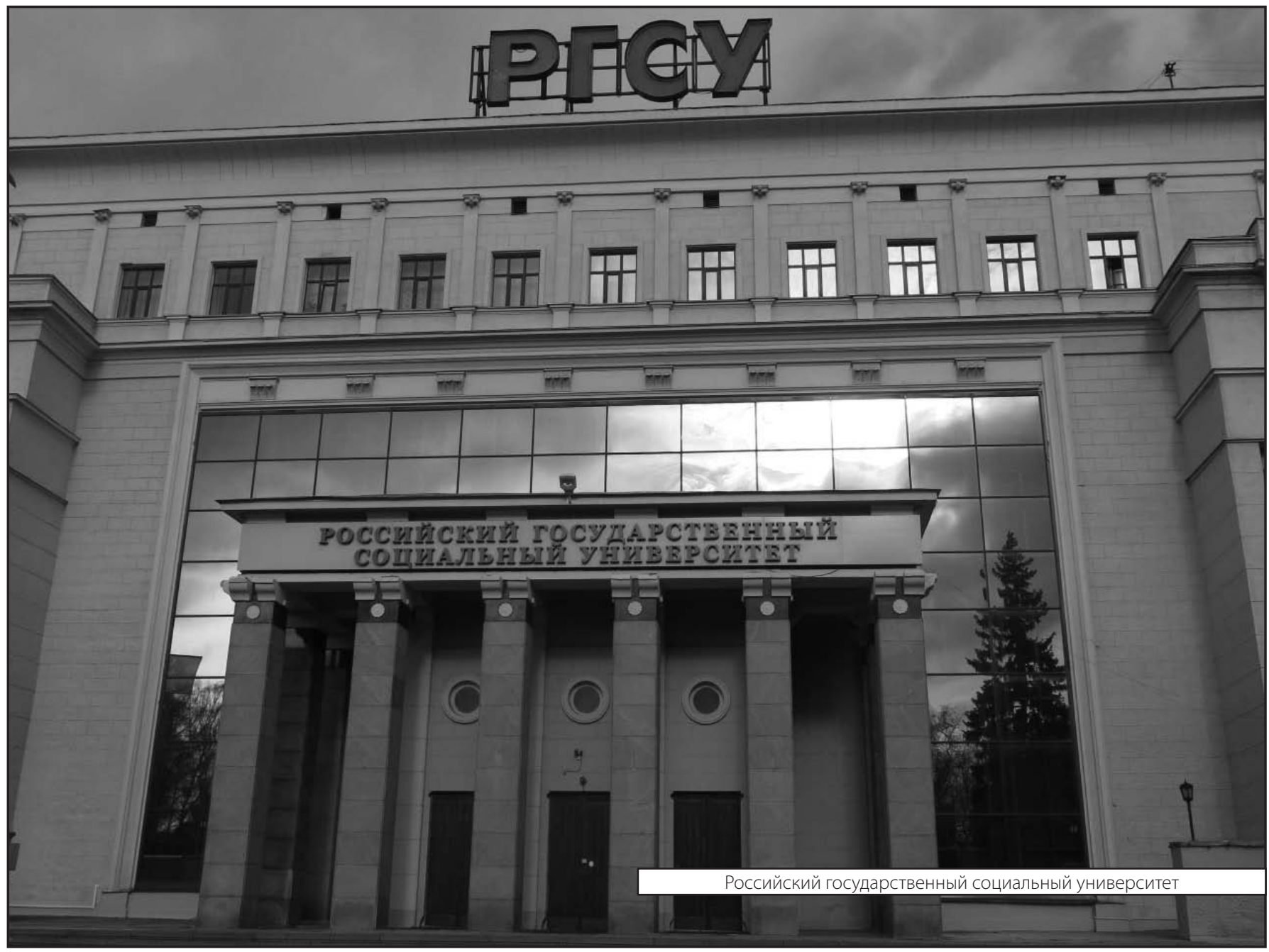

